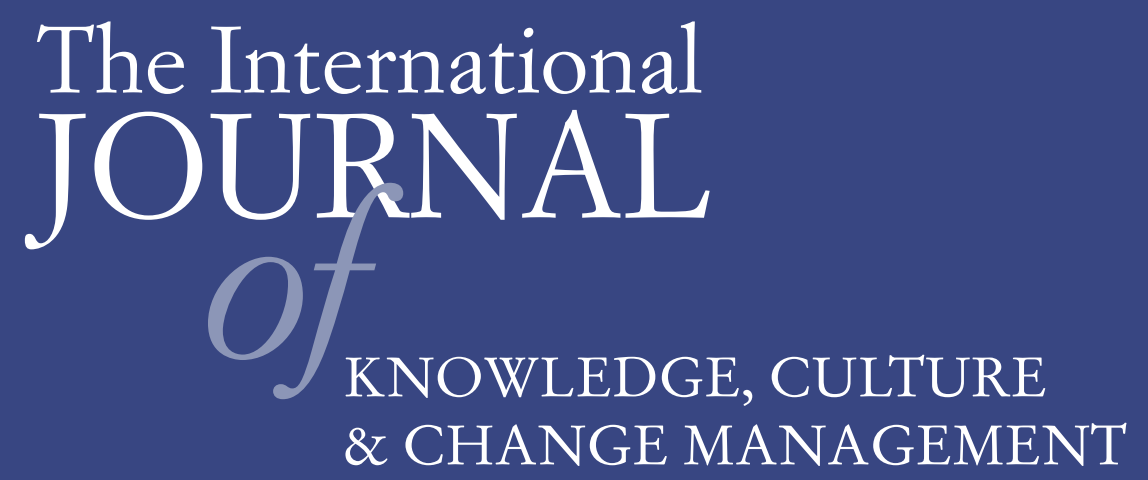

Volume 8, Number 4

Building the Capacity of Learning Professionals through an Infusion of Formal and Informal

Learning

Susan Bolt 
THE INTERNATIONAL JOURNAL OF KNOWLEDGE, CULTURE AND CHANGE MANAGEMENT http://www.Management-Journal.com

First published in 2008 in Melbourne, Australia by Common Ground Publishing Pty Ltd www.CommonGroundPublishing.com.

(C) 2008 (individual papers), the author(s)

(C) 2008 (selection and editorial matter) Common Ground

Authors are responsible for the accuracy of citations, quotations, diagrams, tables and maps.

All rights reserved. Apart from fair use for the purposes of study, research, criticism or review as permitted under the Copyright Act (Australia), no part of this work may be reproduced without written permission from the publisher. For permissions and other inquiries, please contact <cg-support@commongroundpublishing.com>.

ISSN: $1447-9524$

Publisher Site: http://www.Management-Journal.com

THE INTERNATIONAL JOURNAL OF KNOWLEDGE, CULTURE AND CHANGE MANAGEMENT is a peer refereed journal. Full papers submitted for publication are refereed by Associate Editors through anonymous referee processes.

Typeset in Common Ground Markup Language using CGCreator multichannel typesetting system http://www.CommonGroundSoftware.com. 


\title{
Building the Capacity of Learning Professionals through an Infusion of Formal and Informal Learning
}

\author{
Susan Bolt, Curtin University of Technology, Western Australia, AUSTRALIA
}

\begin{abstract}
The success of many organisations depends on their capacity to learn and because of this learning professionals in the fields of education and training are often engaged to build workforce capacity. The success of this scenario depends on the expertise of these learning professionals, but how is their capacity built? Formal learning is typically standardised, centrally controlled and vertically integrated approaches to the transmission of knowledge through organised curriculum modules that can lead to a qualification. Informal learning is more horizontally integrated, dynamic and occurs when people make a conscious effort to learn from their experiences and engage in individual or group reflection (Burns, 2002; Foley, 2004). In the past formal and informal learning were considered separately but an infusion of formal and informal learning may be a more appropriate approach in this new economy. This paper, based on results from an interpretive study investigating professional development in large Australian organisations in 2007, explores the professional development experiences of staff employed in training and educational organisations. Semi-structured interviews and questionnaires, using mixed methods, were conducted with staff from all levels of these organisations to investigate the relationship between adult learners' professional development and organisations' change agenda. Results indicated that in some situations there was considerable blurring of boundaries between informal and formal learning experiences. The conclusion is made that a balkanised approach to professional development is insufficient to build the capacity of learning professionals in the 21st Century and a more dynamic approach that moves flexibly between formal and informal learning approaches is recommended.
\end{abstract}

Keywords: Formal and Informal Learning, Professional Development

\section{Introduction}

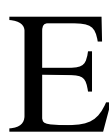

DUCATION AND TRAINING professionals must build their own capacity to learn before they can support client organisations by providing professional advice through consultation, or training and development programs. So, how do trainers and staff developers manage their own professional learning? In order to answer this question, this paper compared the professional learning experiences of trainers in a volunteer organisation, with those of staff developers in a government agency. Data were collected through interviews and surveys as part of an interpretive study conducted in 2007, across three large Australian service providing organisations. The responses of trainers and staff developers were a subset of the overall data collected in the study, because in some cases the services provided by these organisations were broader than the provision of education and training. This paper focused on how different learning professionals used formal and informal learning in their own professional development. Furthermore, it explored respondents' perceptions of the pros and cons of formal and informal learning. Literature pertaining to adult learning theory, and formal and informal learning was reviewed and details about the research methodology used in this study were included. Finally it was concluded that an infusion of formal and informal learning was most effective in building the capacity of learning professionals to support client organisations.

\section{Adult Learning Theory}

Adults' approach to learning was contextual rather than subject-centred. The concept of 'a contextual approach to learning' needed to be interpreted expansively, as contexts differed among adults, and gender, race and class impacted on adults' learning approaches and opportunities. According to Knowles' (2005) adults needed to know the reasons why they were learning something; how they would learn it, and were most ready to learn when the learning was problem-based and related to their everyday lives. Experience was foundational to adult learning theory. Adults had a repertoire of experiences, and learned from their own and others' experiences. Intrinsic motivation was more likely to spark learning than external factors; however extrinsic motivators played a role and adults were more likely to engage in professional learning during particular phases of their lives and careers. Adults' saw themselves as autonomous, self-directing learners and therefore collaborative planning mechanisms should be used to include adult learners' perspectives and cater for their needs (Houle, 1980, Knowles, Holton III, \&

\section{THE INTERNATIONAL JOURNAL OF KNOWLEDGE, CULTURE AND CHANGE MANAGEMENT, VOLUME 8, NUMBER 4, 2008}


Swanson, 2005; Merriam, Caffarella, \& Baumgartner, 2007).

Experiential learning was a key element of adult learning theory and was consistent with humanist and constructivist approaches to learning, because of its emphasis on making meaning from personal experiences. It was consistent with social learning theory which used practical situations which allowed novices to observe and replicate what more experienced 'mentors' did in the workplace. Dewey, an early protagonist of experiential learning, explored learning in relation to life experiences and highlighted the importance of connecting past and present experiences, in the context of a specific environment (1938 in Merriam et al., 2007). Kolb (1984 in Merriam et al.) built on the work of Dewey and conceptualised the skills required to learn from experience. These skills included the ability to engage with new experiences, observe and reflect, analyse and integrate, make decisions and problem-solve in order to embed new concepts into practice. Jarvis (1987) extended Kolb's conception of experiential learning to include the experiences learners brought with them to the situation. Furthermore Jarvis differentiated between reflective and non-reflective learning, and concluded that individuals did not always learn from their experiences - sometimes they remained unchanged (Burns, 2002; Jarvis, 1987; Knowles et al., 2005; Merriam et al.).

Self-directed learning was another important aspect of adult leaning theory, which was also consistent with humanism. Self-directed learning was driven by the learner but could be facilitated by teachers in learning centres. Employers often used online learning modules to facilitate self-directed learning. There was minimal research investigating the relationship between self-directed learning and organisational learning. Even so, Confessore and Kops (1998 in Cho, 2002; Ellinger, 2004) identified environmental characteristics of workplaces that were conducive to developing learning organisations, self-directed learning, transformational learning and problembased learning. These environmental characteristics, consistent with McGregor's (1964 in Robbins, Millett, \& Waters-Marsh, 2004) 'Theory Y', included participatory leadership, collaboration, and formal and informal opportunities for people to learn (Burns, 2002; Knowles et al.; Merriam et al.).

\section{Formal and Informal Learning}

Formal learning, in the shape of formal education and non-formal programs arose from the liberal tradition of cognitive learning, and from the behaviourist tradition of Taylorism. Formal education occurred in universities, technical and further adult education facilities (TAFE), and registered training organisa- tions (RTO). Courses were structured around specific curriculum and learners gained a qualification as a result of their successful completion of units and assessment items. Universities provided a liberal education to increase learners' knowledge and understanding, typically through cognitive learning approaches which favoured teacher-centred transmission of knowledge, although the benefits of other approaches to learning may be recognised and used in some cases. The behaviourist competency-based learning approach developed skills and was favoured by TAFEs and RTOs in their training packages. Competency-based learning was becoming increasingly popular in the Australian training context. Nonformal programs developed knowledge or skills in relation to specific workplace needs and may involve sequenced learning but did not result in a qualification on completion of the course. The duration of non-formal programs differed from hours, to days, to weeks or months and often involved spaced learning (Burns, 2002; Foley, 2004; Smith, 1998; Sork \& Newman, 2004).

Informal learning occurred when people consciously tried to learn from their experiences and often involved discussion, and group or individual reflection, but did not involve formal instruction (Foley, 2004). This type of learning was influenced by Dewey's conception of experiential learning and Lindeman's emphasis on democratic approaches to learning through discussion (Sork \& Newman, 2004). Caffarella (2002) unlike most program developers recognised the importance of transfer of learning and included "transfer of learning techniques" in formal program development (Caffarella, 2002, p.16). These 'techniques' relied on informal learning strategies, such as coaching, mentoring, tuning protocols, networking, and action research. Colleagues acted as critical friends when they coached learners to adjust their behaviour. A more experienced mentor worked with a mentee over time to promote professional learning and increase career opportunities. Tuning protocols focused on fine tuning work practices and provided a framework for presentation, questioning reflection and discussion in a supportive environment. Networking occurred face-to face or online when collegiate groups of people communicated to share ideas, problem-solve or provide mutual support. Action research used various configurations of planning, acting, describing and evaluating to apply research principles to problem-solving (Caffarella, 2002). Informal learning extended beyond these examples and included participation in forums, committees and meetings, and professional reading. 


\section{Research Methodology}

The issue of how best to plan and implement training and development programs to build the capacity of individuals and organisations was at the heart of this interpretive Australian mixed methods study. Stratified, purposeful sampling methods were used to select representative sample populations within the three participating organisations. Two of these organisations were government agencies and one was a volunteer organisation. All three organisations provided a service to the public. The volunteer organisation (Case One) and one of the government agencies (Case Three) were RTOs. The volunteer organisation operated as an RTO to provide a service to the community and revenue to support its volunteer functions. Although the government agency, Case Three, was an RTO, it outsourced much of its training to external providers and therefore performed mostly administrative functions. The public service provided in Case Three was transport, not education and training. Case Two, also a government agency, provided professional advice and support for schools through professional development and other services.

Survey data was collected concerning background, organisational change, formal education, non-formal programs, informal learning and incidental learning, and analysed using SPSS. Quantitative survey results reported in this paper represented responses from all 218 respondents, regardless of their roles. This research was exploratory in nature and therefore limited to an overview of the situation rather than an indepth investigation of a narrower range of phenomena. For example, comprehension of the range of participants' engagement with learning opportunities was sought rather than the delivery and impact of specific programs.

Exploratory interviews were conducted with the CEO in Case One who was also the Training Manager; a District Director and Manager of Education Services in Case Two; the Manager of Training, and the Manager of Professional Development in Case Three. These interviews provided a strategic overview of change initiatives and the professional development. Semi-structured interviews sought an overall perspective of how individuals experienced organisational change and professional learning. A total of 70 interviews were conducted, but for the purposes of this paper responses of trainers and staff developers were selected and reported. Eight trainers in Case One and nine staff developers in Case Two participated in semi-structured interviews. There were no semi-structured interviews with trainers in Case Three. Qualitative data was analysed using NVivo7. Finally, individual case studies utilising quantitative and qualitative data were developed and cross case analysis was conducted.
The key questions this paper sought to answer were:

1. How was trainers' and staff developers' professional learning managed?

2. What did trainers and staff developers perceive to be the pros and cons of formal and informal learning?

3. What were their recommendations?

\section{Findings}

Findings were presented in relation to these three questions. Respondents' comments were included as supporting evidence. Data from all three organisations were included in relation to the management of professional development and recommendations of best practice, as this information was provided through both exploratory and semi-structured interview questions. Only data from Cases One and Two were used to represent respondents' perceptions of the pros and cons of formal and informal learning, because no trainers or staff developers from Case Three participated in semi-structured interviews.

\section{Management of Professional Learning}

There were different approaches to managing the training and development of learning professionals across the three organisations. In general, senior managers planned formal learning opportunities for staff in response to change initiatives. The CEO, in Case One decided who would participate in which learning opportunities based on organisational needs, and there were no collaborative planning mechanisms in place ... "If there is anything I can give anybody, especially our volunteers who give us so much time, if I can give them a qualification, I am only too pleased to give them the training they need". The organisation derived its income from training and the sales. Government regulations required trainers in RTOs to be appropriately qualified, so all trainers in this organisation, regardless of their prior experience, completed Certificate IV in Training and Assessment (TAA). Some trainers who were not interviewed but completed the survey were qualified teachers and worked with the organisation under a partnership agreement. These respondents were frustrated because their teaching qualifications were not recognised. Similarly other trainers, some of whom were interviewed had worked with the organisation for a number of years and held different versions of this qualification, but were still required to complete the TAA ... "I've done 'Lead Manage and Develop Teams'. I did do 'Train Small Groups' through this other group but I had to do it all again to go on [this] certificate". Others who were interviewed were volunteers who had previously conduc- 

VOLUME 8

ted training without any qualifications. Some of these people were 'stretched' by the requirements of the course.

The staff developers in Case Two were all highly qualified professionals and the issue of completing the TAA did not exist for them. Team managers developed plans, aligned with organisational strategic plans, for the professional development of their teams. Team members participated in centrally developed non-formal programs aligned with organisational change initiatives. For staff developers this usually meant receiving training so they could then deliver this training to clients. Through performance management processes, team members could request additional role related professional development ... "I ensure that there is enough money for training because school psychologists need to value add ... I think that it has been very rare where we have not agreed ... It has to be linked to their performance management".

A human resource planning approach was used in Case Three, supported by a 'Performance Development Process' which "having gone through the goals for the year and any changes ... looking at what we need ... the skills shortages". Access to training and development was negotiated through this process and staff members self-nominated or were nominated by line managers to attend courses which were usually provided by an external provider because "we just don't have the people to do that so we took out a contract with a provider. We [were] the lead organisation, RTO, they work[ed] to us under our quality assurance but they provide [d] all the trainers and the assessors. They do the training for customer service and radio procedures, first aid, safe working - they do that for drivers in the classroom and then there's the driver trainers themselves, the drivers out on the track in their old carriage. There are not a lot of internal trainers available [here] because of obviously resourcing, rostering, and workload".

\section{Perceptions of Pros and Cons of Formal and Informal Learning}

All trainers in Case One participated in formal education (TAA), the cost of which was paid for by the employer. In doing so they received support from the interstate facilitator, whom they could email, and the CEO, with whom they could speak directly. The course increased respondents' currency, credibility and employability, but was conducted mainly online or over the weekends during personal rather than work time. Furthermore, there were long breaks between face-to-face sessions. All trainers were required to complete the TAA, regardless of their prior knowledge and experience ... "I don't have a choice but I've been doing training since 1993 and I did 6 months full time purely on training so I've done all the Certs old BSS BSZs Certificate IV training". Further problems included insufficient mutual planning and lack of opportunity for respondents to fully utilise the training ... "we didn't get a lot of input but as far as TAA, if we are going to have to do it, and the organisation is paying for it to be done, then make it a valuable thing and give us opportunity to use the stuff"... "the majority of assignment work is hypothetical ... designing a course for a hypothetical company on a topic which really exists, but at the end of the day that course is useless to us because we are not going to use it". Consequently experienced trainers felt demotivated ... "it de-motivates me because I look at this and say well I'm already busy enough, but I have to do this, so I lose the interest, lose the motivation". Some volunteers who had not done this type of thing before had difficulty comprehending what was said in emails, opening the $\mathrm{CD}$ and learning online ... "because of the way it's set out, and although they would send me emails it's just something I just can't get my head around". People who had not done the course before also had difficulty with the face-to-face sessions ..." in the class where you've got people who've done more or less than what I have ... there's questions flying everywhere and you get really confused in a room where you've got three different levels". In addition to the TAA, some trainers privately enrolled in university courses such as Emergency Management ... "it does give me that higher level professional development in the management of emergencies and it's not just being on the scene it's about what comes before and what comes after, so I see that role is quite relevant in this organisation".

Respondents in Case One also participated in nonformal programs such as workshops related to the change in first aid protocols ... "they were presented to us before they had to happen and they were presented to us as a complete group in a very structured manner so that everyone knew what they were and when they were going to happen". Although there were some issues about the wording of some of the protocols, respondents were pleased with the way protocol changes were presented. However, there were other changes trainers did not receive training or information about, in a timely manner ... "time it so that you know when it's going to happen and in presenting it make sure that it is presented to everybody as close as possible together and at least before it needs to be known about".

Although survey data indicated respondents in Case One participated in informal learning, in the interviews trainers highlighted the lack of opportunity to learn through informal mechanisms such as staff meetings, discussions and networking ... "we were given facilitator guides which were quite good 
but there it is have a read implement it now ... We had when I say no discussion it was a very small amount of discussion, which was here it is lets have a look at it, this is the new program, implement it from now, no discussion on let's give it a chance to throw it around and have a good look at it". This caused problems for trainers in the classroom ... "it can look rushed because you're stumbling through the resources". Trainers wanted to have time to debrief their training and engage in collegiate discussion prior to implementation so that the most effective delivery was achieved. They perceived a gap between theory and practice ... "we do our training to learn how to deliver training and it gives us certain rules but we breach every one of those rules".

Respondents in Case Two participated in formal education and non-formal programs. Respondents benefited from formal education but paid for it themselves and completed it in their own time. ... “ I needed the most up to date research ... I needed something to direct me into the area that I was interested in and I felt that doing my post grad and Masters would actually help me to focus and it has"... "it's a huge in cost on my life, my time". The cost of participating in non-formal programs was met by the employer and respondents participated in various courses and workshops. Respondents benefitted because the non-formal programs were relevant and based on research ... "they were very well presented, incredible knowledge base; I knew I was working with top of the wozza people”. Unfortunately there was no ongoing support such as mentoring or coaching once the course was over ... "how would you continue that momentum after you finish your training ... if you don't apply it you lose it ... we needed more of that follow up". Sometimes, when follow-up was provided respondents did not access it ... "he offers it online but my head wasn't in that space at the time ... I didn't see that I would actually need that". Other difficulties occurred because of isolated working conditions and a failure to schedule collaborative time for teams to debrief their training and discuss how best to deliver the training ... "your ability to have a unified package for child protection was very difficult because it was very hard to get everyone into the same area at the same time and have an agreed way of presenting the package". In addition to these non-formal programs some respondents attended conferences, which were beneficial when they included lots of hands on activities, movement, humour and practical resources ... "it was great because we had a couple of different venues and lots of hands on activities so really involving everybody to get lots of good feedback ... we actually got draft samples of some of the books for free so it was that kind of stuff as well as a big file. You've actually got something to show for what you went away for, so you can share them with your work colleagues". They were less effective if participants were "just sitting there and somebody talking to you all the time".

Respondents in Case Two participated in informal learning such as study tours and mentoring. For example, a senior manager received funding to go on a study tour he developed ... "to help develop my understandings of what effective school system quality assurance is all about ... so that was a good learning experience ... out of that work I wrote a paper that focused on the critical success factors for school system quality assurance so that certainly in my mind consolidated my personal perspectives on world's best school quality assurance should be". As a result of the study tour and the paper, an "Associate Reviewer Program' was developed to provide professional development for principals across the district. Although many benefited from the 'Associate Reviewer Program', the opportunity to engage in study tours was not open to many people. Furthermore, new team members were successfully mentored by people who had been in similar jobs for a longer time. In other circumstances, colleagues who had attended workshops together tried to mentor each other to keep the momentum going but it was less successful because ... "we were working with just the knowledge we had and we probably needed a higher level of knowledge to support us in actually implementing that".

\section{Recommendations}

In summary, respondents made the following recommendations:

1. Recognise and use the skills and abilities of staff

2. Provide practical, relevant, tailored training and development

3. Follow-up formal learning with informal learning processes

4. Provide opportunity for implementation of learning in the workplace 

VOLUME 8

\section{Survey Results}

Table 1: Extract of Pertinent Cross Case Survey Results

\begin{tabular}{|c|c|c|c|c|c|}
\hline \multicolumn{3}{|c|}{ Category Frequencies } & Case 1 & Case 2 & Case 3 \\
\hline \multicolumn{3}{|c|}{ Number of responses } & 40 & 76 & 102 \\
\hline \multicolumn{3}{|c|}{ Response Rate } & $80 \%$ & $72 \%$ & $69 \%$ \\
\hline \multirow{3}{*}{\multicolumn{2}{|c|}{ Highest level of education }} & High School & $33 \%$ & $7 \%$ & $25 \%$ \\
\hline & & TAFE & $30 \%$ & $12 \%$ & $17 \%$ \\
\hline & & University & $33 \%$ & $75 \%$ & $48 \%$ \\
\hline Gender & \multicolumn{2}{|l|}{$\begin{array}{l}\text { Male } \\
\text { Female }\end{array}$} & $\begin{array}{l}43 \% \\
57 \%\end{array}$ & $\begin{array}{l}24 \% \\
76 \%\end{array}$ & $\begin{array}{l}55 \% \\
45 \%\end{array}$ \\
\hline $\begin{array}{l}\text { Type of } \\
\text { work }\end{array}$ & \multicolumn{2}{|c|}{$\begin{array}{l}\text { Management } \\
\text { Supervisory } \\
\text { Professional } \\
\text { Admin Support } \\
\text { Skilled Tradesman } \\
\text { Manual labouring } \\
\text { Student } \\
\text { Technical } \\
\text { Other } \\
\text { (Respondents could choose more than one category) }\end{array}$} & $\begin{array}{l}23 \% \\
25 \% \\
40 \% \\
23 \% \\
3 \% \\
5 \% \\
3 \% \\
8 \% \\
15 \%\end{array}$ & $\begin{array}{l}21 \% \\
10 \% \\
71 \% \\
21 \% \\
- \\
- \\
1 \% \\
2 \% \\
-\end{array}$ & $\begin{array}{l}15 \% \\
19 \% \\
44 \% \\
35 \% \\
2 \% \\
- \\
- \\
11 \% \\
-\end{array}$ \\
\hline $\begin{array}{l}\text { Formal } \\
\text { Educa- } \\
\text { tion }\end{array}$ & \multicolumn{2}{|c|}{$\begin{array}{l}\text { Participation (total percentage) } \\
\text { Liberal education (subset of total percentage) } \\
\text { Competency-based programs } \\
\text { Learning needs were met fully, or to a major extent } \\
\text { Personal learning needs } \\
\text { Organisational learning needs }\end{array}$} & \begin{tabular}{|l|}
$63 \%$ \\
$5 \%$ \\
$89 \%$ \\
$52 \%$ \\
$40 \%$ \\
\end{tabular} & $\begin{array}{l}26 \% \\
66 \% \\
26 \% \\
30 \% \\
25 \%\end{array}$ & $\begin{array}{l}41 \% \\
43 \% \\
50 \% \\
26 \% \\
10 \%\end{array}$ \\
\hline $\begin{array}{l}\text { Non-form- } \\
\text { al Pro- } \\
\text { grams }\end{array}$ & \multicolumn{2}{|c|}{$\begin{array}{l}\text { Participation (total percentage) } \\
\text { Workshops (subset of total percentage) } \\
\text { Lectures } \\
\text { One-day courses } \\
\text { Conferences } \\
\text { Learning needs were met fully, or to a major extent } \\
\text { Personal learning needs } \\
\text { Organisational learning needs }\end{array}$} & $\begin{array}{l}95 \% \\
22 \% \\
16 \% \\
15 \% \\
11 \% \\
40 \% \\
40 \%\end{array}$ & $\begin{array}{l}87 \% \\
21 \% \\
15 \% \\
18 \% \\
20 \% \\
46 \% \\
35 \%\end{array}$ & $\begin{array}{l}73 \% \\
23 \% \\
17 \% \\
16 \% \\
17 \% \\
30 \% \\
20 \%\end{array}$ \\
\hline $\begin{array}{l}\text { Informal } \\
\text { Learning }\end{array}$ & \multicolumn{2}{|c|}{$\begin{array}{l}\text { Participation (total percentage) } \\
\text { Mentoring (subset of total percentage) } \\
\text { Team-based learning } \\
\text { Networking } \\
\text { Professional reading } \\
\text { Learning needs were met fully, or to a major extent } \\
\text { Personal learning needs } \\
\text { Organisational learning needs }\end{array}$} & $\begin{array}{l}80 \% \\
15 \% \\
14 \% \\
12 \% \\
11 \% \\
59 \% \\
56 \%\end{array}$ & $\begin{array}{l}86 \% \\
9 \% \\
14 \% \\
18 \% \\
16 \% \\
45 \% \\
43 \%\end{array}$ & $\begin{array}{l}66 \% \\
13 \% \\
10 \% \\
14 \% \\
13 \% \\
30 \% \\
21 \%\end{array}$ \\
\hline $\begin{array}{l}\text { Incidental } \\
\text { Learning }\end{array}$ & \multicolumn{2}{|c|}{$\begin{array}{l}\text { Participation (total percentage) } \\
\text { Working with others (subset of total percentage) } \\
\text { Talking with colleagues } \\
\text { Doing the job } \\
\text { Learning needs were met fully, or to a major extent } \\
\text { Personal learning needs } \\
\text { Organisational learning needs }\end{array}$} & $\begin{array}{l}90 \% \\
22 \% \\
20 \% \\
20 \% \\
50 \% \\
53 \%\end{array}$ & $\begin{array}{l}92 \% \\
21 \% \\
23 \% \\
22 \% \\
29 \% \\
29 \%\end{array}$ & $\begin{array}{l}80 \% \\
23 \% \\
23 \% \\
26 \% \\
40 \% \\
30 \%\end{array}$ \\
\hline
\end{tabular}




\section{Discussion}

Demographic data indicated trainers and staff developers were well represented in Cases One and Two in "professional" and "other roles". The highest frequency of formal education occurred in Case One, where respondents had the lowest frequency of highly qualified staff, more significantly however, change initiatives were directly related to the acquisition of formal qualifications for trainers. The TAA represented a significant proportion of the competency-based training undertaken in Case One. In spite of senior managers' focus on providing formal learning opportunities, there were high frequencies of participation in informal and incidental learning across all cases. It was likely that informal learning occurred as a result of organisational planning, and respondents' self-directed learning. Incidental learning occurred naturally as a result of situations and experiences. Even though access to professional development was determined according to organisational needs, respondents stated it was more effective in meeting personal needs. Although respondents' opportunities to participate in mutual planning processes varied, the perception of their needs being met indicated their interest in learning.

Formal and informal learning were valued for different reasons. Formal learning provided qualifications and equipped respondents with knowledge, skills and understandings. Informal learning facilitated transfer of learning in the workplace and allowed respondents to learn from their own and others' experiences, but it was rarely included in training and development agenda. Trainers and staff developers identified the need for collegiate discussion after formal training sessions to develop and enhance effective delivery strategies. The need for follow-up after formal learning programs, in the form of coaching and mentoring was also identified. Using informal learning in this way was consistent with Caffarella's (2002) "transfer of learning techniques", and social learning theory, humanist and constructivist approaches to learning. Embedding informal learning in training and development agenda was also consistent with the philosophies of Dewey and Lindeman who advocated experiential learning and the use of discussion (Sork \& Newman, 2004). However senior managers appeared to have been heavily influenced by liberalism and Taylorism and favoured cognitive and behaviourist approaches to learning when they developed training agenda for staff development (Sork \& Newman, 2004). It was recognised by a trainer in Case One, that the prin- ciples of adult learning were often overlooked when it came to the provision of their own training and development (Knowles et al.; Merriam et al.). The need for a quick turn around from training to implementation was often the reason for this hasty oversight. However it was likely, better results could be achieved by scheduling time for trainers and staff developers to reflect on their learning and engage in 'transfer of learning strategies'. This could also improve morale and enhance motivation because adult learners preferred to own and direct their learning in response to real needs in the workplace (Knowles et al.; Merriam et al.).

\section{Conclusion}

This paper reviewed literature pertaining to adult learning theory, formal and informal learning, which provided a background to this interpretive research conducted in 2007 in Australian service providing organisations. Key findings from the study were presented and the perceptions of trainers and staff developers were highlighted. The approach taken by managers to the training and development of learning professionals was based on organisational needs and included the provision of formal learning opportunities. Informal learning was sometimes overlooked in these plans. However, respondents participated in formal and informal learning. The prior knowledge and experience of respondents was recognised in some cases but not in others. The perceptions of trainers and staff developers in relation to the pros and cons of formal and informal learning were provided for Cases One and Two only, because training was outsourced to external providers in Case Three and therefore no trainers were interviewed. Respondents were pleased with formal learning opportunities provided by employers because it increased their knowledge, skills and understandings, credibility and employability. However it was problematic if it encroached on personal time, did not recognise respondents' experience or expertise, or could not be implemented in the workplace. For transfer of learning to occur there needed to be real opportunities in the workplace to put learning into practice. It could also be enhanced through informal learning techniques such as discussion, coaching and mentoring. Recommendations were made supporting these findings. It was concluded that formal and informal learning provided complementary learning opportunities and therefore both should be planned for and included in training and development programs.

\section{References}

Burns, R. (2002). The adult learner at work ( $2^{\text {nd }}$ ed.). Sydney: Allen and Unwin. 
Caffarella, R.S. (2002). Planning programs for adult learners: A practical guide for educators, trainers and staff developers. San Francisco: Jossey-Bass.

Cho, D. (2002). The connection between self-directed learning and the learning organisation. [Electronic version]. Human Resource Development Quarterly, 13, 467-470. Retrieved December 20, 2007, from ABI/INFORM Global database.

Ellinger, A.D. (2004). The concept of self-directed learning and its implications for human resource development [Electronic version]. Advances in Developing Human Resources, 6, 158-177. Retrieved December 12, 2005 from ABI/INFORM Global database.

Foley, G. (2004). Introduction: The state of adult education and learning. In G. Foley (Ed.), Dimensions of adult learning (pp. 3-18). Sydney: Allen and Unwin.

Houle, C.O. (1980). Continuing learning in the professions. San Francisco: Jossey-Bass.

Jarvis, P. (1987). Adult learning in the social context. Beckenham: Croom Helm Ltd.

Knowles, M.S., Holton III, E.F., \& Swanson, R. A. (2005). The adult learner: The definitive classic in adult education and human resource development $\left(6^{\text {th }}\right.$ ed.). Burlington, MA: Elsevier Inc.

Merriam, S.B., Caffarella, R.S., \& Baumgartner, L.M. (2007). Learning in adulthood: A comprehensive guide (3 ${ }^{\text {rd }}$ ed.). San Francisco: Jossey-Bass.

Robbins, S.P., Millett, B., \& Waters-Marsh, T. (2004). Organisational Behaviour (4 ${ }^{\text {th }}$ ed.). Frenchs Forrest: Pearson Education Australia.

Smith, A. (1998). Training and development in Australia ( $2^{\text {nd }}$ ed.). Sydney: Butterworths.

Sork, T., \& Newman, M. (2004). Program development in adult education and training. In G. Foley (Ed.), Dimensions of adult learning (pp. 96-117). Sydney: Allen and Unwin.

\section{About the Author}

Susan Bolt

Susan Bolt provides administrative, consultancy and professional learning services for divisional academic staff at Curtin Business School with the aim to improve teaching and learning. Currently she is investigating the relationship between adult learners' professional development and organisations' change agenda in diverse Australian organisations. Her previous work included management of system and district teacher professional development programs and research into pedagogical renewal through action learning. 


\section{EDITORS}

Mary Kalantzis, University of Illinois, Urbana-Champaign, USA.

Bill Cope, University of Illinois, Urbana-Champaign, USA.

\section{EDITORIAL ADVISORY BOARD}

Verna Allee, Verna Allee Associates, California, USA.

Zainal Ariffin, Universiti Sains Malaysia, Penang, Malaysia.

Robert Brooks, Monash University, Melbourne, Australia.

Bruce Cronin, University of Greenwich, UK.

Rod Dilnutt, William Bethway and Associates, Melbourne, Australia.

Judith Ellis, Enterprise Knowledge, Melbourne, Australia.

Andrea Fried, Chemnitz University of Technology, Germany.

David Gurteen, Gurteen Knowledge, UK.

David Hakken, University of Indiana, Bloomington, Indiana, USA.

Sabine Hoffmann, Macquarie University, Australia.

Stavros loannides, Pantion University, Athens, Greece.

Margaret Jackson, RMIT University, Melbourne, Australia.

Paul James, RMIT University, Melbourne, Australia.

Leslie Johnson, University of Greenwich, UK.

Eleni Karantzola, University of the Aegean, Rhodes, Greece.

Gerasimos Kouzelis, University of Athens, Greece.

Krishan Kumar, University of Virginia, USA.

Martyn Laycock, University of Greenwich and managingtransitions.net, UK.

David Lyon, Queens University, Ontario, Canada.

Bill Martin, RMIT University, Melbourne, Australia.

Pumela Msweli-Mbanga, University of Kwazulu-Natal, South Africa.

Claudia Schmitz, Cenandu Learning Agency, Germany.

Kirpal Singh, Singapore Management University, Singapore.

Dave Snowden, Cynefin Centre for Organisational Complexity, UK.

Chryssi Vitsilakis-Soroniatis, University of the Aegean, Rhodes, Greece.

Please visit the Journal website at http://www.Management-Journal.com for further information about the Journal or to subscribe. 


\title{
THE UNIVERSITY PRESS JOURNALS
}

\author{
International Journal of the Arts in Society \\ Creates a space for dialogue on innovative theories and practices in the arts, and their inter-relationships with society. \\ ISSN: 1833-1866 \\ http://www.Arts-Journal.com
}

International Journal of the Book

Explores the past, present and future of books, publishing, libraries, information, literacy and learning in the information society. ISSN: 1447-9567

http://www.Book-Journal.com

Design Principles and Practices: An International Journal

Examines the meaning and purpose of 'design' while also speaking in grounded ways about the task of design and the use of designed artefacts and processes. ISSN: 1833-1874 http://www.Design-Journal.com

International Journal of Diversity in Organisations, Communities and Nations

Provides a forum for discussion and builds a body of knowledge on the forms and dynamics of difference and diversity. ISSN: $1447-9583$ http://www.Diversity-Journal.com

International Journal of Environmental, Cultural, Economic and Social Sustainability

Draws from the various fields and perspectives through which we can address fundamental questions of sustainability. ISSN: 1832-2077

http://www.Sustainability-Journal.com

Global Studies Journal

Maps and interprets new trends and patterns in globalization. ISSN 1835-4432 http://www.GlobalStudiesJournal.com

International Journal of the Humanities

Discusses the role of the humanities in contemplating the future and the human, in an era otherwise dominated by scientific, technical and economic rationalisms. ISSN: 1447-9559 http://www. Humanities-Journal.com

International Journal of the Inclusive Museum

Addresses the key question: How can the institution of the museum become more inclusive? ISSN 1835-2014 http://www.Museum-Journal.com

International Journal of Interdisciplinary Social Sciences

Discusses disciplinary and interdisciplinary approaches to knowledge creation within and across the various social sciences and between the social, natural and applied sciences.

ISSN: 1833-1882

http://www.Socialsciences-Journal.com

International Journal of Knowledge, Culture and Change Management

Creates a space for discussion of the nature and future of organisations, in all their forms and manifestations.

ISSN: $1447-9575$

http://www.Management-Journal.com

International Journal of Learning

Sets out to foster inquiry, invite dialogue and build a body of knowledge on the nature and future of learning.

ISSN: $1447-9540$

http://www.Learning-Journal.com

International Journal of Technology, Knowledge and Society

Focuses on a range of critically important themes in the various fields that address the complex and subtle relationships between technology, knowledge and society. ISSN: 1832-3669 http://www.Technology-Journal.com

Journal of the World Universities Forum

Explores the meaning and purpose of the academy in times of striking social transformation. ISSN 1835-2030

http://www.Universities-Journal.com

\author{
FOR SUBSCRIPTION INFORMATION, PLEASE CONTACT \\ subscriptions@commonground.com.au
}

